\title{
Microwave Plasma Chemical Vapor Deposition of Nano-Structured Sn/C Composite Thin-Film Anodes for Li-ion Batteries
}

\author{
M. Marcinek, L. J. Hardwick, T. J. Richardson, X. Song and R. Kostecki* \\ Environmental Energy Technologies Division \\ Lawrence Berkeley National Laboratory \\ Berkeley, CA 94720, USA
}

\begin{abstract}
In this paper we report results of a novel synthesis method of thin-film composite $\mathrm{Sn} / \mathrm{C}$ anodes for lithium batteries. Thin layers of graphitic carbon decorated with uniformly distributed Sn nanoparticles were synthesized from a solid organic precursor Sn(IV) tert-butoxide by a one step microwave plasma chemical vapor deposition (MPCVD). The thin-film Sn/C electrodes were electrochemically tested in lithium half cells and produced a reversible capacity of 440 and $297 \mathrm{mAhg}^{-1}$ at C/25 and 5C discharge rates, respectively. A long term cycling of the $\mathrm{Sn} / \mathrm{C}$ nanocomposite anodes showed $40 \%$ capacity loss after 500 cycles at $1 \mathrm{C}$ rate.
\end{abstract}

Keywords: Sn/C; Lithium Batteries; Anode; Plasma; Microwave

*Corresponding author.

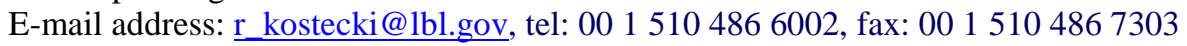




\section{Introduction}

The development of new cathode and anode materials meets an extensive market demand for an advanced generation of lithium batteries with greater energy densities and improved cycle life properties. In most of the conventional Li-ion systems, graphitic anodes are used as an intercalation host for lithium to form $\mathrm{LiC}_{6}$, which corresponds to a charge capacity of $372 \mathrm{mAhg}^{-1}$. An extensive number of experimental approaches have been proposed to increase the anode's electrochemical capacity [1,2]. Several modifications of carbons $[3,4,5,6,7]$, nitrides $[8,9]$, oxides $[10,11,12,13,14]$ or alloying of lithium with metals such an Si [15], Sn [16] and Al [17] were proposed. Among them, tin seems to be particularly attractive since it easily and reversibly alloys with $\mathrm{Li}$ atoms at potentials $<1.1 \mathrm{~V}$ vs. Li. Other attractive properties of tin include fast Li diffusion, better safety, easy mechanical processing, and crucially, a high gravimetric $993 \mathrm{mAhg}^{-1}$ and volumetric $7262 \mathrm{mAhcm}^{-3}$ specific theoretical capacities [18,19,20].

The first commercially available amorphous tin-based composite anode was introduced to the market by Sony in 2006 [21], followed by detailed studies of $\mathrm{Sn}_{0.34} \mathrm{Co}_{0.19} \mathrm{C}_{0.47}$ systems by Dahn et al. [22], which demonstrated the capabilities of these electrodes in high energy Li-ion systems.

Unfortunately one of the major obstacles to the use of pure tin as an active material is its large volumetric expansion during the alloying with lithium, which causes cracking and mechanical disintegration of Sn particles. Loss of mechanical and electronic integrity of the active material leads to severe degradation of the composite anode upon 
cycling and dramatically shortens the cycle life of the electrode. One proposed resolution to overcome this problem is to use tin oxide as a soft matrix to ameliorate the expansion of the metal $[23,24,25,26,27]$. Alternative solutions include the use of tin alloys $[28,29,30,31,32,33,34,35,36,37,38,39,40,41]$ and other tin based composite materials such as $\mathrm{LiSn}_{2}\left(\mathrm{PO}_{4}\right)_{3}$ [20]. Minimizing the thickness of the electrode, as well as reducing the particle size [42] and uniform particle distribution within the supporting matrix [43], can help accommodate the mechanical stress induced in the crystalline lattice of $\mathrm{Li}_{x} \mathrm{Sn}$. This can have the effect of preventing particle agglomeration and improving long-term electrochemical performance.

$\mathrm{Sn}, \mathrm{SnO}_{2}$ and Sn-based alloy composites with graphite [44,45,46,47], amorphous carbon $[48,49]$ or carbon nanotubes [50] used as a mechanical support and conductive matrix for tin-based active material particles also offer a unique opportunity to combine the stable cyclability of the carbon with the high storage capacity of tin-based materials. Fabrication techniques of nano-structured $\mathrm{Sn}, \mathrm{SnO}_{2}$ and carbon/tin composites include autocatalytic deposition [44], ball-milling [41,45,51], chemical reduction [46,50], electrodeposition [47], hydrolysis [48], pyrolysis [49,] sputtering [52], plasma laser deposition (PLD) [53], sol-gel techniques [54], partial reduction [55], precipitation [56], sonochemical methods [57], and vapor deposition [58]. However, these processes often involve several time consuming steps and offer only limited control of the particle size and distribution. Moreover, typical $\mathrm{Sn}, \mathrm{SnO}_{2}$ and $\mathrm{Sn}$-based alloy anodes are prepared by using the conventional lamination method which involves slurry preparation (grinding, mixing with binders and solvents), laminating, drying, heating etc. 
In this work we present a new, one step microwave plasma chemical vapor deposition (MPCVD) of nano-dispersed tin-carbon composite thin-film anodes for Li-ion batteries. This experimental approach provides an easy, fast and inexpensive method for the direct formation of thin films of uniformly distributed ultra-fine grains of metal within an electronically conductive graphitic matrix [59].

\section{Experimental}

A detailed description of the experimental setup can be found in [59]. The $\mathrm{Sn} / \mathrm{C}$ film can be produced on various types of conductive and non-conductive substrate materials from a tin-based organic salt precursor without using stabilizers or reducing agents. In this work, a small amount $(\sim 2 \mathrm{mg})$ of the $\mathrm{Sn}(\mathrm{IV})$ tert-butoxide $\mathrm{Sn}\left(\mathrm{OC}\left(\mathrm{CH}_{3}\right)_{3}\right)_{4}$ (Sigma-Aldrich) organic precursor was placed $\sim 5 \mathrm{~mm}$ from a substrate $\left(\sim 1 \mathrm{~cm}^{2}\right.$ piece of $\mathrm{Cu}$ foil or glass) in a Pyrex glass tube reactor. The deposition process was carried out for $6 \mathrm{~s}$ at $1200 \mathrm{~W}$ microwave radiation power, which produced a $\sim 5 \mu \mathrm{m}$ thick nanocomposite $\mathrm{Sn} / \mathrm{C}$ film. The qualitative analysis of the $\mathrm{Sn} / \mathrm{C}$ films by inductively coupled plasma (Perkin Elmer Optima 5300DV ICP-OES ) spectroscopy produced a C/Sn mass ratio of 2.5:1, i.e., much higher than in the $\operatorname{Sn}(\mathrm{IV})$ tert-butoxide (1.6:1). The thickness and composition of the film were reproducible and not dependent on the type of substrate.

The structure of carbon in composite $\mathrm{Sn} / \mathrm{C}$ films was analyzed by Raman microscopy (Labram, ISA Group Horiba) with a laser excitation wavelength of either 632.8 or $488 \mathrm{~nm}$, at $1 \mathrm{~mW}$ power at the sample surface. The morphology of the thin-film and the nanoparticle size were characterized by transmission electron microscopy (TEM, 
model JEOL 200CX), and scanning electron microscopy (SEM, model Hitachi S-4300 SE/N. An X-ray powder diffraction pattern of a Sn/C thin-film deposited on a glass substrate was obtained using a Philips X-Pert PRO diffractometer operating in BraggBrentano mode with $\mathrm{Cu} \mathrm{K} \alpha$ radiation. The $2 \theta$ step size was $0.017^{\circ}$ and counting time 400 s per step. The whole pattern fitting process was carried out using Powdercell software $[60]$.

Electrochemical characterization was conducted in a He-filled glove box (VAC Inc.) with a model 273A Princeton Applied Research electrochemical station. The tests were carried out in a three electrode cell equipped with Li foil reference and counter electrodes and filled with the 1.0 $\mathrm{M} \mathrm{LiPF}_{6} \mathrm{EC} / \mathrm{DMC}(1: 1 \mathrm{w} / \mathrm{w})$ electrolyte. The cyclic voltammetry measurements were performed at $0.1 \mathrm{mVs}^{-1}$.

\section{Results}

Figure 1 shows the X-ray diffraction pattern of the $5 \mu \mathrm{m}$ thick $\mathrm{Sn} / \mathrm{C}$ film. The low intensity of the pattern is due primarily to the high porosity of the film. The only phase clearly observed is elemental Sn (I4 $/$ /amd). The refined tetragonal lattice parameters $a_{0}$ and $c_{0}$ are $5.86 \AA$ and $3.19 \AA$, respectively. These are slightly larger than the bulk values

$5.831 \AA$ and $3.176 \AA$, as is common for small particles. The average Sn crystallite size calculated using the Scherrer equation was $\sim 15 \mathrm{~nm}$.

SEM images (Figure 2a and $\mathrm{b}$ ) of the surface morphology and cross-section of the Sn/C composite layer display a uniform thin-film of fairly constant thickness ca. 5-6 $\mu \mathrm{m}$. 
The morphology of this porous film is consistent in the film bulk and at the surface. The film is made up of large $300-600 \mathrm{~nm}$ agglomerates. According to supplementary observations (data not shown here) the aggregates consist of small disoriented crystallites. The domains form an interconnected network with a micro- and nano-porous "lava rock" structure. The EDX spectrum of the Sn/C film (Figure 2c) shows strong signals characteristics for $\mathrm{L}$ tin family at $\left(\mathrm{SnL}_{1}\right)$ 3.156, $\left(\mathrm{SnL}_{\alpha 2}, \mathrm{SnL}_{\alpha 1}\right)$ 3.414, $\left(\mathrm{SnL}_{\beta 1}\right.$, $\left.\mathrm{SnL}_{\beta 4}, \mathrm{SnL}_{\beta 3}\right)$ 3.600, $\left(\mathrm{SnL}_{\beta 2}\right)$ 3.929, $\left(\mathrm{SnL} \gamma_{1}\right) 4.07 \mathrm{keV}$, carbon $\left(\mathrm{CK}_{\alpha}\right) 0.27 \mathrm{keV}$ and copper substrate $\left(\mathrm{CuL}_{\alpha 1}\right) 0.94 \mathrm{keV}$. A small contribution from oxygen at $\left(\mathrm{OK}_{\alpha}\right) 0.53 \mathrm{keV}$ suggests the presence of tin oxide impurities in the layer [61].

The typical Raman spectra of a C/Sn thin-film recorded at two excitation wavelengths 632.8 and $488 \mathrm{~nm}$ are displayed in Figure 3. The spectrum recorded at 632.8 $\mathrm{nm}$ wavelength exhibits two intense peaks assigned as the G- and D-band at 1583 and $1323 \mathrm{~cm}^{-1}$ that correspond to the $E_{2 \mathrm{~g}}$ and $A_{1 \mathrm{~g}}$ carbon vibration modes, respectively [62]. The D-band is associated with the break in symmetry occurring at the edges of the graphite sheets. A shoulder at $1620 \mathrm{~cm}^{-1}$, known as the D'-band, is also attributed to discontinuity and disorder within graphene planes, but the exact nature of this peak is still under dispute $[63,64,65]$.

The presence of strong graphite $\mathrm{G}$ and $\mathrm{D}$ modes along with the absence of a sharp diamond Raman peak at $\sim 1330 \mathrm{~cm}^{-1}$ in the Raman spectra suggests that the C/Sn films consist mainly of a $\mathrm{sp}^{2}$-coordinated carbon phase. The location of the G-band that is typical for graphite and carbon blacks is quite insensitive to the excitation wavelength. 
However, the observed shift of the D-band position from 1323 to $1344 \mathrm{~cm}^{-1}$ and the decreased peak intensity as the laser excitation is varied from 632.8 to $488 \mathrm{~nm}$ represents typical spectral behavior of nano-crystalline graphite with a high degree of disorder $[66,67]$.

TEM imaging was used to investigate the size and distribution of tin particles as well as the local structure of carbon in the Sn/C film. The dark-field TEM picture of the $\mathrm{Sn} / \mathrm{C}$ composite is shown in Figure 4a. The dark-field technique allows clear observation of particle morphology and the distribution of $\mathrm{Sn}$ on the surface of the $\mathrm{Sn} / \mathrm{C}$ deposit. The dark contrast area is attributed to carbon, whereas light contrast spots represent $\mathrm{Sn}$ nano particles. The images show a remarkably uniform and fine dispersion of tin in the C/Sn composite. To determine the Sn particle size distribution in the $\mathrm{Sn} / \mathrm{C}$ film, one hundred randomly selected Sn particles from the magnified TEM images were measured. The statistical representation of the $\mathrm{Sn}$ particle size distribution is displayed in Figure $4 \mathrm{~b}$. The particle size distribution is very narrow; the calculated average size of Sn particles (ca. $2.75 \mathrm{~nm}$ ) is noticeably smaller than the average particle size estimated from the X-ray data. The discrepancy between XRD and TEM particle sizes could be due to the presence of a small number of larger particles that contribute strongly to the XRD pattern. While they may represent a small fraction of the particles, they could represent a significant fraction of the mass of $\mathrm{Sn}$.

The HRTEM image of the $\mathrm{Sn} / \mathrm{C}$ agglomerate (Figure 5) reveals a few 1-5 $\mathrm{nm} \mathrm{Sn}$ particles (dark areas) that are fully embedded in partially graphitized, carbonaceous material. The presence of nanocrystalline tin particles was confirmed by their electron diffraction patterns (not shown here). Interestingly, the carbon shows relatively large c.a. 
$10-15 \mathrm{~nm}$ well-organized graphene domains in the bulk of the agglomerate as well as in locations adjacent to the Sn particles. It also displays regions where shorter layers of irregular shape prevail, which are typical of carbon blacks [68].

The thin-film $\mathrm{Sn} / \mathrm{C}$ anode was characterized by cyclic voltammetry (CV) in the 1.0 $\mathrm{M} \mathrm{LiPF}_{6}$ EC/DMC (1:1 w/w) electrolyte at $0.1 \mathrm{mVs}^{-1}$ scan rate (Figure 6a). The CV profile is typical for tin, tin-based alloys or $\mathrm{SnO}_{2}$ composites after several cycles where the Sn material is formed from tin oxide reaction with lithium in the first cycle. A weak cathodic peak at $0.98 \mathrm{~V}$ occurs only during the first scan and may be attributed to the irreversible reduction of the tin oxide impurities or the formation of the SEI layer. The peak at $0.65 \mathrm{~V}$ is usually attributed to early stages $\left(\mathrm{Li}_{\mathrm{x}} \mathrm{Sn}, \mathrm{x}<1\right)$ of the $\mathrm{Li}-\mathrm{Sn}$ alloying process. The large and broad cathodic peak at $0.37 \mathrm{~V}$ corresponds to the formation of highly lithiated phases i.e., $\mathrm{Li}_{4.4} \mathrm{Sn}, \mathrm{Li}_{2.33} \mathrm{Sn}$. The anodic scan exhibits four distinct peaks at $0.48,0.62,0.73$, and $0.8 \mathrm{~V}$, which correspond to the delithiation of $\mathrm{Li}_{4.4} \mathrm{Sn}_{2} \mathrm{Li}_{2.33} \mathrm{Sn}$, LiSn, and $\mathrm{Li}_{0.4} \mathrm{Sn}$ phases, respectively [28].

The $\mathrm{Sn} / \mathrm{C}$ thin-film anodes display a relatively large reversible discharge capacity of $c a .440 \mathrm{mAhg}^{-1}$ (calculated for the total mass of the Sn/C layer). Interestingly, no contribution to reversible capacity from the carbon support at potentials $<0.25 \mathrm{~V}$ was observed unless the $\mathrm{Sn} / \mathrm{C}$ anode was polarized at $0 \mathrm{~V}$ for a prolonged period of time (not shown here). The reversible capacity originates exclusively from Sn nanoparticles and reaches $\sim 880 \mathrm{mAhg}^{-1}$ of the $\mathrm{Sn}$ present in the film, which is close to the theoretical value of $993 \mathrm{mAhg}^{-1}$. Interestingly, the cathodic scan of the voltammogram displays a 
considerable contribution from the SEI layer formation, which is much larger than expected for tin metal but smaller than is usually observed for $\mathrm{SnO}$. This is also clearly visible during the galvanostatic cycles that are shown in Figure 6b. The chargedischarging profiles display plateaus characteristic for tin but also show a significant contribution from the irreversible capacity (c.a. $400 \mathrm{mAhg}^{-1}$ ) in the first cycle. We postulate that the irreversible capacity is mainly associated with the SEI layer formation on the carbon matrix and some small contribution from tin.

The cycling performance of the $\mathrm{Sn} / \mathrm{C}$ composite anode is illustrated in Figure $7 \mathrm{a}$. The galvanostatic charge-discharge cycling was continued over 500 cycles at $1 \mathrm{C}$ rate and showed only $40 \%$ capacity fading, which presents a significant improvement if compared with the electrochemical properties of tin based carbon composite materials reported in the literature. Veeraraghavan et al. [44] reported 35 cycles at C/15 and 15.8\% discharge capacity loss for the Sn coated graphite materials. Carbon-tin composites produced by ball milling showed a capacity drop from 1070 to $380 \mathrm{mAhg}^{-1}$ over 20 cycles [45]. Tingraphite materials prepared by chemical reduction of $\mathrm{SnCl}_{4}$ showed the initial reversible massic capacity of $630 \mathrm{mAhg}^{-1}$, which decayed to $415 \mathrm{mAhg}^{-1}$ after 25 cycles [46]. Tin nanoparticles embedded in microporous carbon matrices [48] showed a discharge capacity of $305 \mathrm{mAhg}^{-1}$ after 30 cycles at C/10 rate whereas tin-filled carbon nano-tubes showed remarkable $844 \mathrm{mAhg}^{-1}$ for 40 cycles at C/10 [50].

To evaluate the power capability of the Sn/C composite anode the thin-film electrode was tested at different discharge rates. Figure $7 \mathrm{~b}$ shows the discharge curves at 
$\mathrm{C} / 20, \mathrm{C} / 10, \mathrm{C} / 5,1 \mathrm{C}$ and $5 \mathrm{C}$ rates, which correspond to 423, 400, 386, 349 and 297 $\mathrm{mAhg}^{-1}$, respectively. Such an improved rate performance as compared to $160.5 \mathrm{mAhg}^{-1}$ at $2 \mathrm{C}$ for the Sn-coated graphite [44] or $200 \mathrm{mAhg}^{-1}$ at $1.5 \mathrm{C}$ for Sn-Co-C alloys [51] suggests that vacuum deposition techniques to manufacture nano-structured metal-carbon thin-film anodes may indeed be a promising technology for new generation lithium-ion batteries.

The improved electrochemical behavior of the $\mathrm{Sn} / \mathrm{C}$ composite anode is mainly due to the high lithium diffusion coefficient at room temperature, high porosity of the film, and fine dispersion of Sn nanoparticles, which are embedded in the 3-dimensional carbon matrix. The 3-D composite design allows the accommodation of dimensional changes of Sn nanoparticles and the preservation of the structural and electronic integrity of the $\mathrm{Sn} / \mathrm{C}$ electrode during cycling. The observed decrease of the reversible capacity is likely related to large tin clusters or particles, which are weakly bound to the surface of the carbon aggregates. The network-like 3-D architecture of the $\mathrm{Sn} / \mathrm{C}$ thin-film provides mechanical support and good electrical contact between Sn active material and the current collector. The nanometer size of Sn particles helps contain stress that arises from the expansion/contraction of the crystalline lattice of $\mathrm{Li}_{\mathrm{x}} \mathrm{Sn}$ during charge-discharge processes and prevents particle decrepitation and the degradation of the composite anode.

\section{Conclusions}

In summary, we demonstrated a novel synthesis technique for the production of nanocomposite anodes for Li-ion batteries. The MPVCD co-synthesis of a nanostructured $\mathrm{Sn} / \mathrm{C}$ composite thin-film described in this study presents a simple, fast, and 
inexpensive method for the one-step formation of electronically-conductive, carbon/metal composite binderless thin-films, which can be deposited on any type of substrate. The fast plasma discharge and the presence of microwave radiation accelerate the formation of sites suitable for in situ heterogeneous nucleation, and consequently, the growth and uniform dispersion of tin nanoparticles in the carbonaceous matrix. The electrochemical response of the $\mathrm{Sn} / \mathrm{C}$ thin-film electrode in Li-ion system displays reversible chargedischarge activity, which is attributed mainly to $\mathrm{Sn}$ nanoparticles. The thin-film $\mathrm{Sn} / \mathrm{C}$ electrodes delivered a reversible capacity of 440 and $297 \mathrm{mAhg}^{-1}$ at C/25 and 5C discharge rates, respectively. A long term cycling of the $\mathrm{Sn} / \mathrm{C}$ anodes showed $40 \%$ capacity loss after 500 cycles at $1 \mathrm{C}$ rate. The improved electrochemical behavior of the $\mathrm{Sn} / \mathrm{C}$ thin-film composite anode is mainly due to the high porosity of the film and fine dispersion of Sn nanoparticles, which are embedded in the 3-dimensional carbon matrix.

\section{Acknowledgements}

This work was supported by the Assistant Secretary for Energy Efficiency and Renewable Energy, Office of FreedomCAR and Vehicle Technologies of the U.S. Department of Energy under Contract No. DE-AC02-05CH11231. The authors acknowledge the assistance of the National Center for Electron Microscopy, Lawrence

Berkeley Lab, which is supported by the U.S. Department of Energy under Contract \# DE-AC02-05CH11231.

\section{References}

1. R.A. Huggins, M.Winter, J.O. Besenhard in: J.O. Besenhard (Ed), Handbook of 
Battery Materials, , Wiley, New York (1999). pp 359-381.

2. Y. P. Wu, E. Rahm, R. Holze, Electrochim. Acta, 47 (2002) 3491-3507.

3. M.Yoshio, H.Wang, K. Fukuda, Y. Hara, Y. Adachi, J. Electrochem. Soc.,147 (2000) 1245-1250.

4. M. Yoshio, H. Wang, K. Fukuda, T. Umeno, T. Abe Z. Ogumi, J. Mater. Chem., 14 (2004) 1754-1758.

5. M Yoshio, H. Wang, K Fukuda, Angewandte Chem. Intern. Ed., 42 (2003) 42034206.

6. E. Peled, C. Menachem, D. Bar-Tow, A. Melman, J. Electrochem. Soc., 143 (1996) L4-L7.

7. H. Buqa, P. Golob, M. Winter, J. O. Besenhard, J. Power Sources, 97-98 (2001) 122125.

8. T. Shodai, S. Okada, S. Tobishima, J. Yamaki, J. Power Sources, 68 ( 1997) 515518.

9. S. Suzuki, T. Shodai, Solid State Ionics, 116,(1999) 1-9.

10. J.J. Auborn, Y.L. Barbero, J. Electrochem. Soc., 134, (1987) 638-643.

11. E. Ferg, J. Gummow, A. de Kock, M.M. Thackeray, J. Electrochem. Soc. 141 (1994) L147-L150.

12. T. Ohzuku, A. Ueda, N. Yamamoto, J. Electrochem. Soc., 142 (1995)1431-1435.

13. S.Y. Huang, L. Kavan, I. Exnar, M. Gratzel, J. Electrochem. Soc., 142 (1995) L142L144.

14. M.A. Cochez, J.C. Jumax, P. Lavela, J. Morales, J. Olivier-Fourcade, J.L. Tirado J. Power Sources, 62 (1996) 101-105. 
15. A. Netz, R.A. Huggins, W. Weppner, J. Power Sources, 119-121 (2003) 95-100..

16. S. Yang, P. Y. Zavalij, M.S. Whittingham, Electrochem. Commun., 5 (2003) 587590.

17. Y. Hamon, T. Brousse, F. Jousse, P. Topart, P. Buvat and D.M. Schleich, J. Power Sources, 97-98 (2001) 185-187.

18. K.D Kepler, J.T. Vaughey, M.M. Thackeray, J. Power Sources, 81 (1999) 383-387.

19. M. Egashira, H. Takatsuji, S. Okada, J. Yamaki, J. Power Sources, 107 (2002) 56-60.

20. Ch. M. Burba, R. Frech, J. Electrochem. Soc. 152 (2005) A1233-1240.

21. H. Inoue, Abstract \#228, International Meeting on Lithium Batteries, Biarritz, France, June 18-23, 2006.

22. R.B. Lewis, A. Timmons, R.E. Mar, J.R. Dahn, J. Electrochem. Soc., 154 (2007) A213-A216.

23. Y. Idota, T. Kubota, A. Matsufuji, Y. Maekawa, T. Miyasaka, Science, 276, (1997) 1395-1397.

24. S.H. Ng, D.I. dos Santos, S.Y. Chew, D. Wexler, J. Wang, S.X. Dou, H.K. Liu, Electrochem. Commun., 9 (2007) 915-919.

25. A. Yu, R. Frech, J. Power Sources, 104 ( 2002) 97-100.

26. S. Panero, G. Savo, B. Scrosati, Electrochem. Solid-State Lett., 2 (1999) 365-366.

27. R.A. Huggins, Solid State Ionics, 113-115 (1998) 57-67.

28. M. Winter, J.O. Besenhard, Electrochim. Acta, 45 (1999) 31-50 and refernces therein.

29. Ou Mao, R. A. Dunlap, J.R. Dahn, J. Electrochem. Soc., 146 (1999) 405-413.

30. Ou Mao, J.R. Dahn, J. Electrochem. Soc., 146 (1999) 423-427.

31. Ou Mao, J.R. Dahn, J. Electrochem. Soc., 146 (1999) 414-422. 
32. L. Y. Beaulieu and J. R. Dahn, J. Electrochem. Soc., 147 (2000) 3237-3241.

33. J.R. Dahn, R.E. Mar, Alyaa Abouzeid, J. Electrochem. Soc., 153 (2006) A361-367.

34. J.O. Besenhard, M. Wachtler, M. Winter, R. Andreaus, I. Rom, W. Sitte, J. Power Sources, 81-82 (1999) 268-272.

35. L.Y. Beaulieu, K.C. Hewitt, R.L. Turner, A. Bonakdarpour, A.A. Abdo, L. Christensen, K.W. Eberman, L.J. Krause, J.R. Dahn, J. Electrochem. Soc., 150 (2003) A149-A156.

36. T.D. Hatchard, J.M. Topple, M.D. Fleischauer, J.R. Dahn, Electrochem. Solid-State Lett., 6 (2003) A129-A132.

37. T.D. Hatchard, M.N. Obrovac, J.R. Dahn, J. Electrochem. Soc., 153 (2006) A282A287.

38. J.R. Dahn, R.L. Turner, Ou Mao, R.A. Dunlap, A.E. George, M.M. Buckett, D.J. McClure, L.J. Krause, Thin Solid Films, 408 (2002) 111-122.

39. A. Bonakdarpour, K.C. Hewitt, T.D. Hatchard, M.D. Fleischauer, J.R. Dahn, Thin Solid Films, 440 (2003) 11-18.

40. T.D. Hatchard, J.R. Dahn, S. Trussler, M. Fleischauer, A. Bonakdarpour, J.R. Mueller-Neuhaus, K.C. Hewitt, Thin Solid Films, 443 (2003) 144-155.

41. G.M. Ehrlich, C. Durand, X. Chen, T.A. Hugener, F. Spiess, S.L. Suib, J. Electrochem. Soc., 147 (2000) 886-891.

42. L. Yuan, Z.P. Guo, K. Konstantinov, H.K. Liu, S.X. Dou, J. Power Sources, 159 (2006) 345-348.

43. I.A. Courtney, W.R. McKinnon, J.R. Dahn, J. Electrochem. Soc., 146 (1999) 59-68. 44. B. Veeraraghavan, A. Durairajan, B. Haran, B. Popov, R. Guidotti, J. Electrochem. 
Soc., 149 (2002) A675-A681.

45. G.X. Wang, J. Ahn, M.J. Lindsay, L. Sun, D.H. Bradhurst, S.X. Dou, H.K. Liu, J. Power Sources, 97-98 (2001) 211-215.

46. L. Balan, R. Schneider, P. Willmann, D. Billaud, J. Power Sources 161 (2006) 587593.

47. W.A. Ulus, Yu. Rosenberg, L. Burstein, E. Peled, J. Electrochem. Soc., 149 (2002) A635-A643.

48. I. Grigoriants, A. Soffer, G. Salitra, D. Aurbach, J. Power Sources, 146 (2005) 185189.

49. L. Yuan, K. Konstantinov, G.X. Wang, H.K. Liu, S.X. Dou, J. Power Sources, 146 (2005) 180-184.

50. T. Prem Kumar, R. Ramesh, Y.Y. Lin, G. Ting-Kuo Fey, Electrochem. Commun., 6 (2004) 520-525.

51. J. Hassoun, G. Mulas, S. Panero, B. Scrosati J. Power Sources, 9 (2007) 2075-2081.

52. W.H. Lee, H.C. Son, H.S. Moon, Y.I. Kim, S.H. Sung, J.Y. Kim, J.G. Lee, J.W. Park, J. Power Sources, 89 (2000) 102-105.

53. N. Kuwata, J. Kawamura, K. Toribami, T. Hattori, N. Sata, Electrochem. Commun., 6 (2004) 417-421.

54. N. Li, Ch. R. Martin J. Electrochem. Soc., 148 (2001) A164-A170.

55. P. Limthongkul, H. Wang, E. Jud, Y. Chiang, J. Electrochem. Soc., 149 (2002) A1237.

56. G.J. Li, S. Kawi, Mater. Lett., 34 (1998) 99-102.

57. D.Aurbach, A.Nimberger, B.Markovsky, E.Levi, E.Sominski, A.Gedanken, Chem. 
Mater., 14 (2002) 4155-4166.

58. Y.Wang, J.Y. Lee, H. C Zeng, Chem. Mater., 17 (2005) 3899-3907.

59. M. Marcinek, X. Song, R. Kostecki, Electrochem. Commun., 9 (2007) 1739-1743.

60. W. Kraus, G. Noltze, Powder Cell for Windows, 2.4, Federal Institute for Materials Research and Testing, Berlin, Germany (2000).

61. J.I. Goldstein, Ch.E. Lyman, D.E. Newbury, E. Lifshin, P. Echlin, L. Sawyer, D.C. Joy, J.R. Michael, "Scanning Electron Microscopy and X-Ray Microanalysis”, Third edition Springer.2003 p.361.

62. F. Tuinstra, J.L. Koenig, J. Chem. Phys., 53 (1970) 1126-1130.

63. R. Saito, A. Jorio, A.G. Souza Filho, G. Dresselhaus, M.S. Dresselhaus, M.A. Pimenta, Phys. Rev. Lett., 88 (2002) 027401-027404.

64. A.C. Ferrari, J. Robertson, Phys. Rev. B, 61 (2000) 14095-14107.

65. M. A. Pimenta, G. Dresselhaus, M. S. Dresselhaus, L.G. Cancado, A. Jorio and R. Saito, Phys. Chem. Chem. Phys. 9 (2007) 1276-1291.

66. R.C. Mani, M.K. Sunkara, R.P. Baldwin, J. Gullapalli, J.A. Chaney, G. Bhimarasetti, J.M. Cowley, A.M. Rao, R. Raod, J. Electrochem. Soc., 152 (2005) E154-E159.

67. A.D. Lueking, H.R. Gutierrez, D.A. Fonseca, E. Dickey, Carbon 45 (2007) 751-759 and references therein.

68. K. Kinoshita, Editor, Carbon-Electrochemical and Physicochemical Properties, John Wiley and Sons, New York (1988), and references therein. 


\section{Figure Captions}

Fig. 1. X-ray diffraction pattern of $\mathrm{Sn} / \mathrm{C}$ composite film on glass. Vertical markers represent peak positions for bulk tetragonal Sn (PDF Reference Pattern 4-673, International Centre for Diffraction Data).

Fig. 2. Micro-Raman spectra of the $\mathrm{Sn} / \mathrm{C}$ composite film recorded at 488 and $632.8 \mathrm{~nm}$ excitation wavelength.

Fig. 3. SEM micrographs of the surface (a), cross-section (b), and the corresponding EDX spectrum (c) of the Sn/C composite thin-film deposited by MPCVD on Cu foil.

Fig. 4. (a) Dark-field TEM image of the Sn/C composite deposited by MPCVD, (b) diagram of Sn particle size distribution in the $\mathrm{Sn} / \mathrm{C}$ composite.

Fig. 5. HRTEM image of the Sn/C nanocomposite synthesized by MPCVD.

Fig. 6. (a) First CV scan of the Sn/C nanocomposite anode. Scan speed rate was 0.1 $\mathrm{mVs}^{-1}$, (b) first two galvanostatic cycles of the $\mathrm{Sn} / \mathrm{C}$ electrode at $1 \mathrm{C}$ rate.

Fig. 7. (a) Discharge capacity of the $\mathrm{Sn} / \mathrm{C}$ thin-film nanocomposite anode during a longterm cycling at room temperature at $1 \mathrm{C}$ rate, (b) discharge capacity of the $\mathrm{Sn} / \mathrm{C}$ anode at different rates (the electrode was charged at $\mathrm{C} / 10$ prior to discharge at given rate ) 